\title{
ANÁLISE DAS TIPOLOGIAS DE LAJES MAIS UTILIZADAS POR CONSTRUTORAS NA
}

\section{CIDADE DE MARAU - RS}

\author{
Dilmar Balbinotte ${ }^{1}$ \\ Lucas Binda Carlesso ${ }^{2}$ \\ Jackson Deliz Ditz ${ }^{3}$
}

\section{RESUMO}

As lajes são elementos estruturais de superfície horizontal, sujeitos principalmente a ações normais ao seu plano. Neste artigo buscou-se fazer uma pesquisa com construtoras da cidade de Marau - RS, através de entrevistas e aplicação de um questionário, para saber qual o sistema construtivo de laje mais utilizado em edificações multifamiliares, as motivações do emprego ou não emprego desta tipologia e a abertura das empresas a diferentes tipos de lajes. Alguns dos principais resultados indicaram que a laje com vigotas pré-moldadas é a mais empregada e que muitas construtoras ainda utilizam práticas construtivas antigas, devido à politica da empresa, combinando seu custo e o padrão construtivo de suas obras.

Palavras-Chave: Tipologias de lajes. Sistemas construtivos. Construtoras.

\section{ABSTRACT}

Slabs are structural elements of horizontal surface, mainly subject to normal actions to their plan. In this article, a search was made with constructors from the city of Marau - RS, through interviews and application of a questionnaire, to know which construction system is the most commonly used slab in multifamily buildings, the use motivations or use not motivations of this type and the availability of companies to use different slabs types. Some of main results showed that slab with precast beams is most used and many constructors using yet old constructive practices, due to company policy, combining your cost and constructive standard of his works.

Keywords: Slabs types. Constructive systems. Constructors.

\footnotetext{
${ }_{1}^{1}$ Acadêmico do curso de Engenharia Civil da Faculdade (IMED). Email: dilmarbalbinotte@gmail.com.

2 Acadêmico do curso de Engenharia Civil da Faculdade (IMED). Email: lucasbindacarlesso@gmail.com.

${ }^{3}$ Docente do curso de Engenharia Civil da Faculdade Meridional (IMED). Email: jackson.ditz@imed.edu.br. Autor para envio de correspondência.
} 


\section{INTRODUÇÃO}

As lajes são os elementos estruturais que têm a função básica de receber as cargas de utilização das edificações, aplicadas nos pisos, e transmiti-las às vigas (ARAÚJO, 2010). As lajes também servem para distribuir as ações horizontais entre os elementos estruturais de contraventamento (efeito diafragma), além de funcionarem como mesas de compressão das vigas " $\mathrm{T}$ ".

Este artigo tem como objetivo analisar o sistema construtivo de laje mais utilizado pelas construtoras em edificações multifamiliares da cidade de Marau - RS, averiguar os pontos pertinentes relacionados à sua utilização e também verificar como está o pensamento das construtoras para a utilização de novos sistemas de laje no futuro.

\section{REFERENCIAL TEÓRICO}

\section{LAJE MACIÇA}

Segundo Rebello (2007) a laje maciça (Figura 1), é uma placa de concreto armado geralmente com plano horizontal, podendo algumas vezes apresentar pequenas inclinações, como quando utilizadas em coberturas. As lajes podem ser apoiadas em vigas locadas no seu contorno ou podem apoiar-se diretamente sobre os pilares, sem vigas intermediárias.

Conforme Carvalho e Pinheiro (2009), as lajes maciças podem apresentar vantagens como execução simples e rápida, deformações e esforços relativamente pequenos e facilidade no lançamento e adensamento do concreto. Mas também apresentam desvantagens, como alto consumo de madeira para fôrmas, alto tempo de execução, limpeza da obra, entre outras.

Figura 1 - Laje maciça 


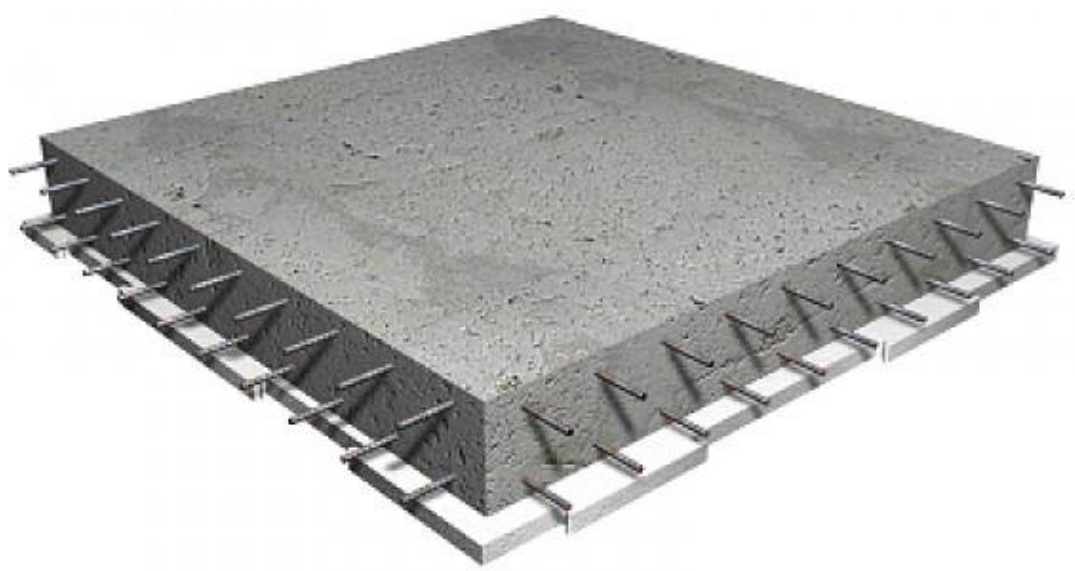

Fonte: REBELLO (2007)

\section{LAJE COM VIGOTAS PRÉ-MOLDADAS}

As chamadas lajes pré-moldadas (Figura 2), conforme define Rebello (2007), não são de fato totalmente pré-moldadas. Alguns elementos como a armação e parte das fôrmas chegam à obra já pronta. Outros, como o concreto da capa e os cimbramentos, são executados in loco. Pela facilidade na sua execução e o consumo de pouca madeira na execução da fôrma, este tipo de laje apresenta-se como a solução mais econômica para vãos até $7,0 \mathrm{~m}$, mas também sendo competitiva para vãos maiores.

Suas vantagens podem ser rapidez e simplicidade na execução, redução de fôrmas de madeira, redução da diversidade de mão de obra, limpeza de obra. Entretanto ela também apresenta algumas desvantagens, tais como menor rigidez na estrutura como um todo, comprimento limitado, limitação de carga de acordo com o fabricante, falta de aderência do concreto da capa com a vigota e a possibilidade de ocorrer fissuras (REBELLO, 2007).

Figura 2 - Laje com vigotas pré-moldadas

Ignis | Caçador | v.6 | n.2 | p. 85-94 | maio/ago. 2017 


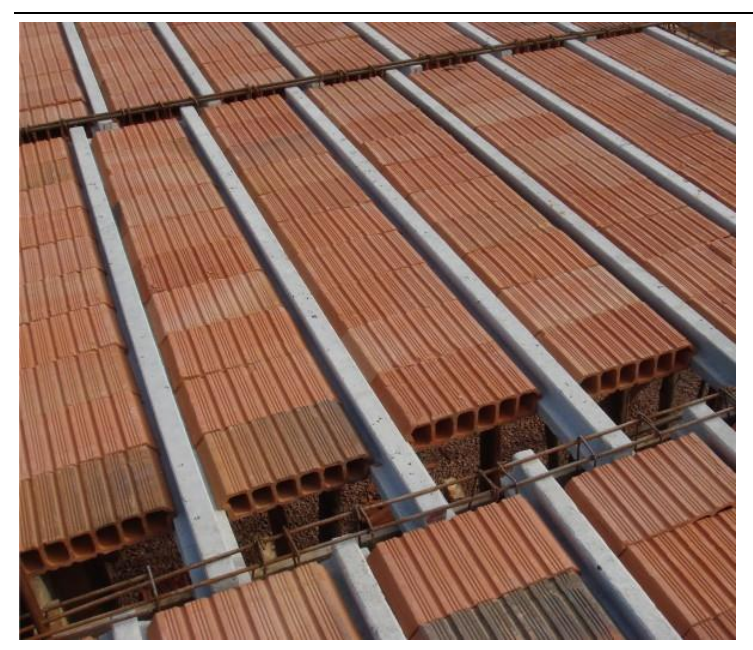

Fonte: REBELLO (2007)

\section{LAJE ALVEOLAR}

No atual mercado da construção civil, existe uma ampla variedade de sistemas de lajes disponíveis, com características que atendem de acordo com a relação sobrecarga/vão, porém, o sistema de lajes alveolares, conforme Figura 3, tem obtido maior destaque na indústria de concreto pré-fabricado. Estas são frequentemente utilizadas numa variedade de projetos em todo o mundo pelo fato de serem eficientes componentes para pavimentos, oferecendo uma solução versátil e, ao mesmo tempo econômica, que pode ser utilizada em diversos tipos de edificações. (PETRUCELLI, 2009).

Petrucelli (2009) define suas vantagens mais importantes como boa produtividade com baixo custo de produção, simplicidade e rapidez de montagem, possibilidade de atingir grandes vãos e redução de materiais e mão de obra. Já suas desvantagens são necessidade de equipamentos de produção e manuseamento, cuidado especial durante o transporte, resistência a flexão transversal limitada devido à ausência de armadura nesse sentido.

Figura 3 - Laje alveolar 


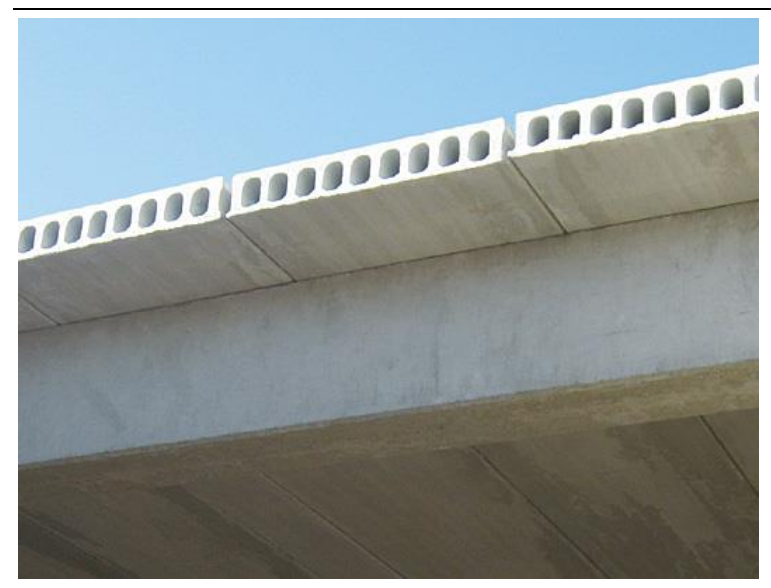

Fonte: REBELLO (2007)

LAJE NERVURADA

A ABNT NBR 6118 (2014) considera em seu item 14.7.7 que as lajes nervuradas (Figura 4) são lajes moldadas no local ou com nervuras pré-moldadas, cuja zona de tração para momentos positivos esteja localizada nas nervuras entre as quais pode ser colocado material inerte. Rebello (2007) afirma que as lajes nervuradas foram idealizadas para permitir um melhor aproveitamento do concreto e diminuir o peso próprio da estrutura.

As principais vantagens das lajes nervuradas, conforme Carvalho e Pinheiro (2009), estão relacionadas à economia de concreto e a utilização em maiores vãos, já suas desvantagens são as dificuldades nas passagens de tubulações e a demanda por alturas maiores do edifício de cada andar.

Figura 4 - Laje nervurada bidirecional

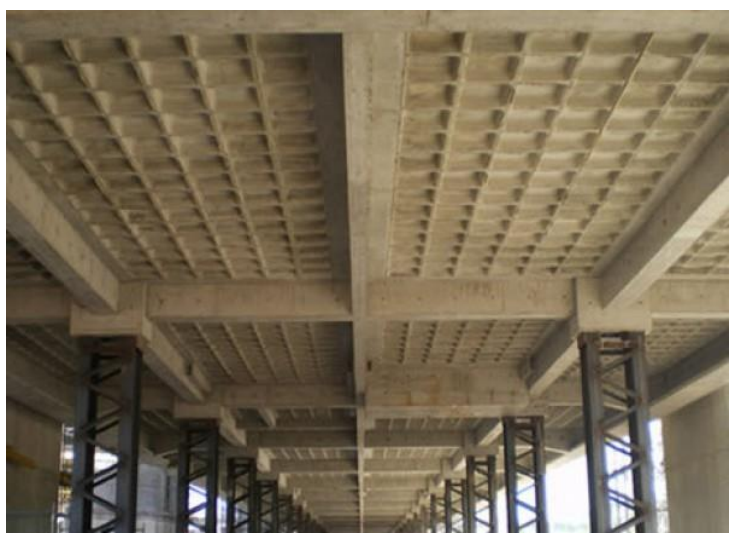

Fonte: REBELLO (2007) 
LAJE PLANA

Segundo Puel (2009), as lajes planas constituem um sistema estrutural interessante em aplicações de projeto, possibilitando alterações de projeto em ambientes internos, pois dispensam a utilização de vigas. As análises desse tipo de laje são complexas e muitas vezes realizadas através de um processo numérico.

Suas principais vantagens podem ser definidas como adaptabilidade de diversas formas ambientais, simplificação das formas, redução da quantidade de cimento, simplificação e racionalização das armaduras. Apesar das inúmeras vantagens, existem também desvantagens que são a verificação da punção das lajes (ver Cordovil, 1997) e a redução da estabilidade global do edifício (PUEL, 2009).

Figura 5 - Laje plana

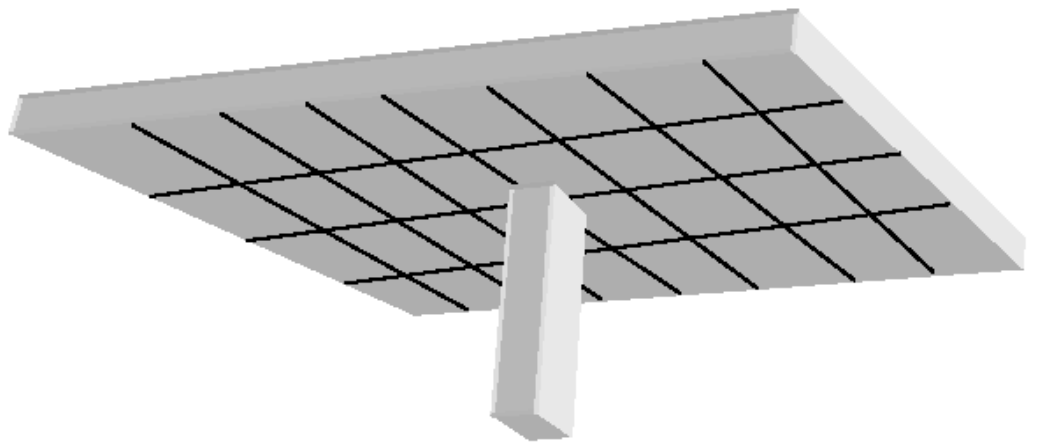

Fonte: PUEL (2009)

\section{DESENVOLVIMENTO}

Com base nas diferentes tipologias de lajes apresentadas no referencial teórico, buscou-se neste trabalho investigar se há predomínio de alguma no uso em edificações multifamiliares da cidade de Marau - RS. Também, objetivou-se conhecer as motivações do emprego ou não emprego de determinado tipo de laje nestas edificações e se as construtoras estão abertas a novas tendências em um futuro próximo.

Para execução da pesquisa, foram realizadas visitas à cinco construtoras desta cidade do noroeste do Rio Grande do Sul. As obras consultadas limitam-se a edificações multifamiliares e a pesquisa foi realizada através de entrevista dos autores com um responsável técnico por cada uma das obras e a aplicação de um 
questionário.

As perguntas elaboradas e aplicadas aos responsáveis tem como base: "Entre as alternativas apresentadas, qual apresenta maior identificação com a empresa em que você trabalha?"

a) Quais os tipos de lajes que a empresa trabalha?

L Laje maciça

Laje com vigotas pré-moldadas

$\square$ Laje alveolar

Laje nervurada bidirecional

$\checkmark$ Laje plana

b) Qual é o tipo de laje mais utilizada?

Laje maciça

Laje com vigotas pré-moldadas

Laje alveolar

$\square$ Laje nervurada bidirecional

$\square$ Laje plana

c) Quais são os pontos determinantes para a escolha deste tipo de laje?

Custo

- Mão de obra

- Disponibilidade na região

- Padrão construtivo

d) Qual o motivo da não utilização de outros tipos de lajes?

Custo

- Política da empresa

- Tipo de edificação

Falta de conhecimento 


\section{Mão de obra}

e) A empresa pretende utilizar novas tipologias de laje no futuro? Por que?

\section{ANÁLISE DOS RESULTADOS}

Os resultados do questionário estão descritos nas Tabelas 1 a 5.

Tabela 1 - Pergunta a)

\begin{tabular}{|c|c|c|c|c|c|c|}
\hline \multicolumn{7}{|c|}{ Quais os tipos de lajes que a empresa trabalha? } \\
\hline \multirow{2}{*}{ Tipos de lajes } & \multicolumn{5}{|c|}{ Empresa } & \multirow{2}{*}{$* \%$} \\
\hline & $A$ & B & C & $D$ & $E$ & \\
\hline Laje maciça & $x$ & $x$ & & $x$ & $x$ & 80 \\
\hline $\begin{array}{l}\text { Laje com vigotas } \\
\text { pré-moldadas }\end{array}$ & $x$ & $x$ & $x$ & $x$ & $x$ & 100 \\
\hline Laje alveolar & & $X$ & $X$ & & & 40 \\
\hline Laje nervurada & & & & $x$ & $x$ & 40 \\
\hline Laje plana & & & & & & 0 \\
\hline
\end{tabular}

Obs.: * Percentual das empresas que utilizam determinado tipo de laje.

Tabela 2 - Pergunta b)

\begin{tabular}{|c|c|c|c|c|c|c|}
\hline \multicolumn{7}{|c|}{ Qual é o tipo de laje mais utilizada? } \\
\hline \multirow{2}{*}{ Tipos de lajes } & \multicolumn{5}{|c|}{ Empresa } & \multirow{2}{*}{$* \%$} \\
\hline & $A$ & $B$ & $\mathrm{C}$ & $D$ & $E$ & \\
\hline Laje maciça & & & & & $x$ & 20 \\
\hline $\begin{array}{l}\text { Laje com vigotas } \\
\text { pré-moldadas }\end{array}$ & $x$ & $x$ & $x$ & & & 60 \\
\hline Laje alveolar & & & & & & 0 \\
\hline Laje nervurada & & & & $x$ & & 20 \\
\hline Laje plana & & & & & & 0 \\
\hline
\end{tabular}

Obs.: * Percentual das empresas mais utilizam determinado tipo de laje.

Tabela 3 - Pergunta c)

Quais são os pontos determinantes para a escolha deste tipo de laje?

Tipos de lajes Empresa 


\begin{tabular}{|l|l|l|l|l|l|l|}
\hline & A & B & C & D & E & \\
\hline Custo & X & & X & X & & 60 \\
\hline Mão de obra qualificada & & & & & $X$ & 20 \\
\hline $\begin{array}{l}\text { Disponibilidade } \\
\text { na região }\end{array}$ & & $X$ & & & & 20 \\
\hline Padrão construtivo & & & & & & 0 \\
\hline
\end{tabular}

Obs.: * Percentual de justificativa das empresas para utilização de determinado tipo de laje.

Tabela 4 - Pergunta d)

\begin{tabular}{|c|c|c|c|c|c|c|}
\hline \multicolumn{7}{|c|}{ Qual o motivo da não utilização de outros tipos de lajes? } \\
\hline \multirow{2}{*}{ Tipos de lajes } & \multicolumn{5}{|c|}{ Empresa } & \multirow{2}{*}{$* \%$} \\
\hline & A & B & C & $\mathrm{D}$ & E & \\
\hline Custo & $\mathrm{x}$ & $\mathrm{x}$ & $\mathrm{X}$ & & & 60 \\
\hline Mão de obra & & & & & & 0 \\
\hline Política da empresa & $X$ & $X$ & & $\mathrm{X}$ & $x$ & 80 \\
\hline Falta de conhecimento & & & & & & 0 \\
\hline Padrão construtivo & & & $X$ & $X$ & $x$ & 60 \\
\hline
\end{tabular}

Obs.: * Percentual de justificativa das empresas para não utilização de determinado tipo de laje.

Tabela 5 - Pergunta e)

\begin{tabular}{|c|c|c|c|c|c|c|}
\hline \multicolumn{7}{|c|}{ A empresa pretende utilizar novas tipologias de laje no futuro? } \\
\hline \multirow{2}{*}{ TIPOS DE LAJES } & \multicolumn{5}{|c|}{ EMPRESA } & \multirow{2}{*}{$* \%$} \\
\hline & A & B & $\mathrm{C}$ & $\mathrm{D}$ & E & \\
\hline Sim & & $x$ & $\mathrm{x}$ & $x$ & $x$ & 80 \\
\hline Não & $X$ & & & & & 20 \\
\hline
\end{tabular}

Obs.: * Percentual das empresas que pretendem ou não utilizar novas tipologias de lajes.

\section{CONCLUSÃO}

Através das pesquisas realizadas com as construtoras em forma de entrevista e aplicação do questionário, pode-se concluir que:

- O tipo de laje que as construtoras mais utilizam em construções multifamiliares é a laje com vigotas pré-moldadas, devido ao seu baixo custo, e da sua fácil disponibilidade na região;

- O fato de as construtoras fabricarem suas próprias vigotas pré-moldadas 
acaba sendo outro ponto determinante na hora da escolha do tipo da laje a ser utilizada;

- Grande parte das construtoras de Marau utilizam práticas construtivas antigas, devido principalmente à política da empresa, combinando com o custo e o padrão construtivo de suas obras;

- 4/5 das empresas consultadas demonstraram estar abertas em buscar inovações para estes elementos estruturais, sempre procurando obter baixo custo, mão de obra qualificada, o que resulta numa boa qualidade do seu produto final.

\section{REFERÊNCIAS}

ARAÚJO, J. M. Curso de concreto armado. 3ed. V2. Rio Grande Dunas,2010.

ASSOCIAÇÃO BRASILEIRA DE NORMAS TÉCNICAS. NBR 6118. Projeto de estruturas de concreto: Procedimento. Rio de Janeiro, 2014.

CARVALHO, R. C.; PINHEIRO, L. M. Cálculo e detalhamento de estruturas usuais de concreto armado. Editora Pini. São Paulo, 2009.

CORDOVIL, F. A. B. Lajes de concreto armado - Punção. Editora UFSC. Florianópolis, 1997.

PETRUCELLI, N. S. Considerações sobre projeto e fabricação de lajes alveolares protendidas. 2009. 106 f. Dissertação (Mestrado em Construção Civil) - Programa de Pós-Graduação em Construção Civil, Universidade Federal de São Carlos, São Carlos.

PUEL, A. Modelagem de lajes planas simétricas e assimétricas em concreto armado análise integrada laje x pilar. Dissertação de mestrado. Universidade Federal de Santa Catarina. Florianópolis, 2009.

REBELLO, P. C. Y. Bases para projeto estrutural na arquitetura. Editora Zigurate. São Paulo, 2007. 